\title{
O REÚSO DA ÁGUA SOB ASPECTOS DA APLICABILIDADE E DETERMINAÇÕES LEGAIS
}

\author{
Andréia de Menezes Olivo ${ }^{1}$ \\ Hamilton Mitsugu Ishiki ${ }^{2}$
}

\begin{abstract}
RESUMO: O reúso da água surge como uma das poucas alternativas para a problemática da escassez da água que parece estar cada vez mais próxima. Além de ser vista como um recurso adicional no gerenciamento dos recursos hídricos, ações como esta podem garantir um futuro menos preocupante quanto às questões relacionadas com a crise da água. O reúso da água visa a redução da utilização da água potável para fins menos nobres, como por exemplo, no setor industrial, agrícola e fins urbanos. Além de impactar diretamente na economia do setor industrial com a redução dos gastos com a água o reúso ajuda diretamente no alívio da utilização dos aquíferos. Neste contexto, o presente artigo apresenta a importância do reúso da água para a sociedade e para o meio ambiente como uma forma de atitude sustentável, apontando diferentes formas de aplicação no setor industrial e abordando a falta de uma legislação específica para o tema em questão.
\end{abstract}

Palavras-chave: Reúso da água. Sustentabilidade. Setor Industrial.

1. Discente do Programa de Mestrado em Meio Ambiente e Desenvolvimento Regional da Universidade do Oeste Paulista - andreiaolivo@yahoo.com.br

2. Docente do Programa de Mestrado em Meio Ambiente e Desenvolvimento Regional da Universidade do Oeste Paulista - hamilton@unoeste.br 


\title{
1. INTRODUÇÃO
}

O ciclo hidrológico garante que a água seja um recurso renovável e abundante, desde que reciclada por mecanismos naturais, processo que garante um recurso limpo e seguro. No entanto, nas últimas décadas, a atividade antrópica tem exercido um papel fundamental na deterioração destes recursos limpos, levando-os à níveis altíssimos de poluição. A vulnerabilidade das águas perante a ação predatória do ser humano justifica a necessidade de implantação de técnicas eficazes e conscientes de reúso da água em diversas modalidades de consumo.

A abordagem de Paz, Teodoro e Mendonça (2000, p.469) sobre o reúso da água define que:

\begin{abstract}
O conceito de uso eficiente de água inclui qualquer medida que reduza a quantidade que se utiliza por unidade de qualquer atividade, e que favoreça a manutenção e a melhoria da qualidade da água. Este uso eficiente está relacionado a outros conceitos de manejo atual dos recursos ambientais, sendo básico para o desenvolvimento sustentável e assegurando que haja recursos suficientes para as gerações futuras (PAZ, TEODORO e MENDONÇA, 2000, p. 469).
\end{abstract}

A soma das atividades humanas, cada vez mais diversificada, associadas ao crescimento populacional, formação de grandes aglomerados urbanos, atividades industriais e agrícolas em expansão, vem exigindo atenção às necessidades de uso da água para as mais variadas finalidades. Concomitantemente existe o dilema de como enfrentar a relação entre a demanda e a oferta de água. As respostas inevitavelmente caem nas questões de políticas públicas mais eficientes e adequadas, como o aumento da eficiência na distribuição da água captada e na implementação de sistemas de gestão efetivas com alternativas de reúso dos recursos hídricos (MANCUSO e SANTOS, 2003).

Um dos maiores desafios de várias comunidades espalhadas pelo mundo é o abastecimento de água, pois a demanda e a seca estão aumentando, os mananciais estão se exaurindo e as reservas subterrâneas estão sendo contaminadas e/ou estão se esgotando. A recuperação das águas, a partir da reciclagem e reúso serão as únicas fontes de suprimento deste recurso e espera-se que, em um futuro próximo, o potencial de recuperação dos efluentes tratados aumente substancialmente. Embora a prática de recuperação e reúso de água sejam empregadas em muitos países, os volumes de água 


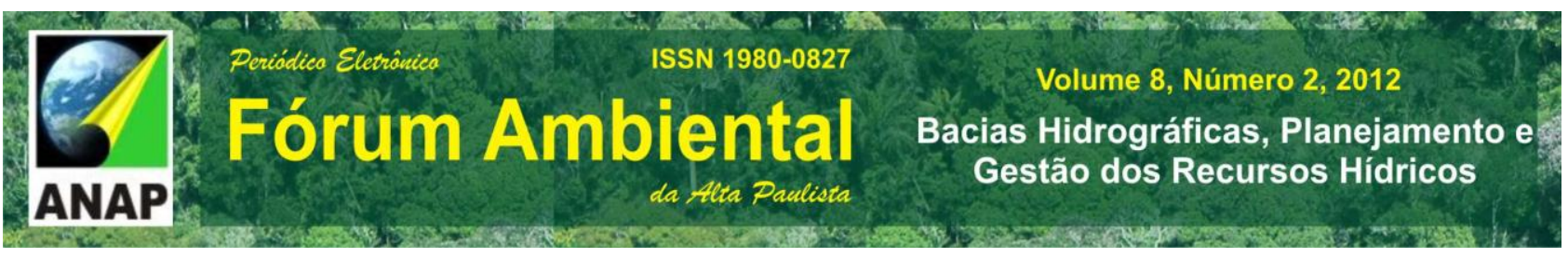

recuperada ainda constituem uma pequena fração do potencial total das cidades e indústrias (MILLER, 2006).

Para Dantas e Sales (2009) o reúso se apresenta como uma das poucas possibilidades de compromisso para reverter o problema da escassez e unir 0 comprometimento social e ambiental, ou seja, a cooperação entre usuários, atividade industrial e agrícola são potenciais fontes restauradoras de água, por meio de planejamento e aplicação da legislação ambiental.

A necessidade da conscientização é inevitável, quando o contexto é a água, a escassez deste recurso não pode ser considerada apenas atributo exclusivo das regiões áridas e semi-áridas. Atualmente, nos conglomerados urbanos a demanda é tão elevada que, mesmo possuindo recursos hídricos em abundância, existe o problema da escassez, fato este que atinge diretamente o desenvolvimento econômico e a qualidade de vida da população.

Implantar técnicas ambientais que ajudam o desenvolvimento humano em sua vivência sustentável é um dos únicos caminhos que resta à atual sociedade. Telles e Costa (2007) afirmam que a conscientização de tais benefícios ainda é muito tímida; sendo uma questão limitada por contextos políticos, culturais, sociais, geográficos e econômicos.

Há alguns anos atrás, o reúso era uma opção exótica, entretanto hoje é uma alternativa necessária para garantir uma expectativa positiva para um futuro próximo, no que se refere aos recursos hídricos. Desta forma, as práticas conservacionistas como o uso eficiente e o reúso da água, mostram que este é um dos principais meios de se ampliar os pontos de abastecimento, sem lançar mão de grandiosos investimentos na ampliação ou construção de plantas de abastecimento urbano de água.

No Brasil, o reúso é uma prática que está sendo cada vez mais necessária e difundida, pois além de ser impulsionada pelos reflexos financeiros está associada aos instrumentos trazidos pela Lei 9.433 de 1997, que visam a implementação da Política Nacional de Recursos Hídricos. As regulamentações específica sobre o assunto ainda são precárias e seria necessária a criação de leis específicas e adequadas para promover a prática do reúso de forma a ampliar os benefícios à toda população, minimizando os 


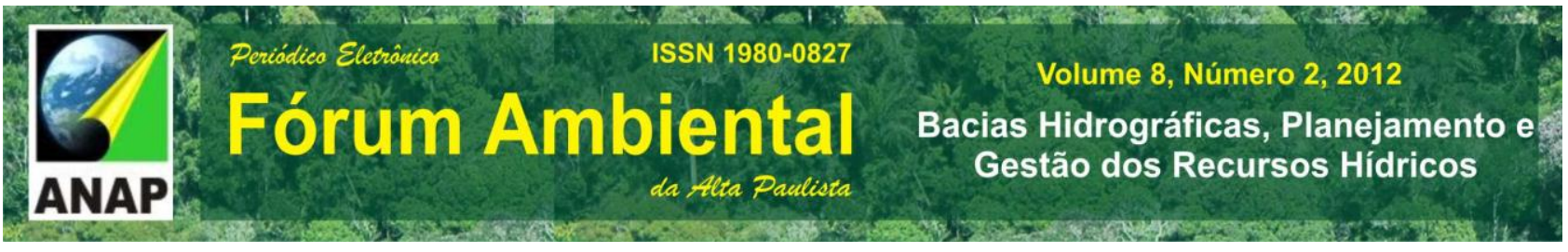

riscos associados à esta técnica e possibilitando o equacionamento dos conflitos potencialmente existentes (RODRIGUES, 2005).

Diante disto, o objetivo deste estudo é apresentar uma descrição das possíveis formas de se reutilizar a água, demonstrando que existem diversas possibilidades de reaproveitamento de um recurso que possivelmente seria descartado, mostrando que os princípios de escassez podem ser minimizados com atitudes sustentáveis e ao mesmo tempo reduzir os custos nos setores industriais, sociedade e meio ambiente. O tema do reúso foi abordado a partir das práticas atualmente empregadas, suas aplicações e benefícios, enfatizando a falta de regulamentações para o setor e os prejuízos que esta lacuna na legislação pode trazer para a aplicação do reúso de água.

A metodologia empregada é uma pesquisa exploratória, descritiva que parte de uma pesquisa bibliográfica baseada em livros, artigos científicos e legislações.

\section{O REÚSO DA ÁGUA: UMA TENDÊNCIA QUE SE AMPLIA DEVIDO AO AUMENTO DA ESCASSEZ E DO PRINCÍPIO DA SUSTENTABILIDADE}

\subsection{A importância do reúso quando relacionado à escassez dos recursos hídricos}

Especialistas e estudiosos do mundo estão atentos à problemática da escassez da água também denominada "crise da água". O estresse e a escassez da água podem estar mais próximos do que a sociedade imagina. De acordo com Spiro e Stigliane (2009) os reservatórios de água estão demonstrando as suas insuficiências acentuadas, sendo que nos períodos de longas estiagens as reservas hídricas estão se exaurindo muito mais rapidamente do que podem ser reabastecidas, devido principalmente à problemas de contexto social, econômico e ambiental.

O desperdício e a escassez de água contribuem para que exista uma demanda crescente por água doce subterrânea, o que está levando a um esgotamento rápido e alarmante dos aquíferos. Existem alguns fatores que contribuem diretamente para este esgotamento, dentre os quais podem ser citados: os ineficientes processos de irrigação colaborando para o desperdício de água de boa qualidade, desordenado e elevado 


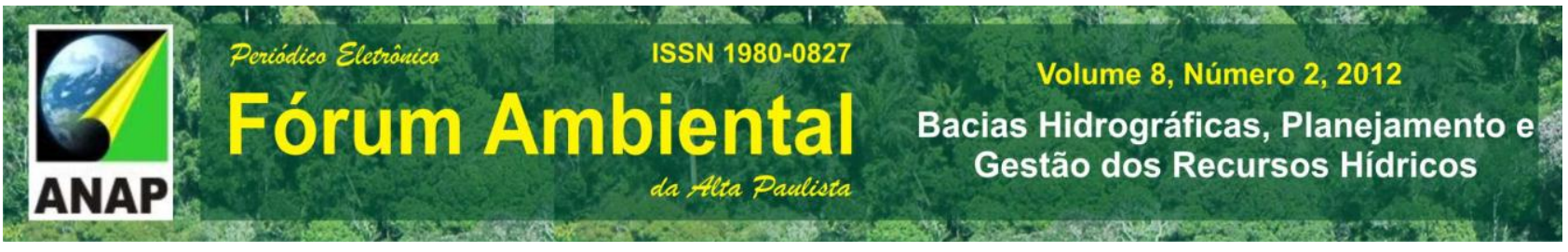

crescimento da população principalmente em regiões áridas, mais pobres e menos desenvolvidas e consumo exagerado pelo setor industrial.

Quando se analisa a atual situação da escassez da água é inevitável considerá-la como sendo um dos maiores problemas do século. Existem alguns fatores que contribuem diretamente para este esgotamento, podendo ser citados: i) ineficientes processos de irrigação, colaborando para o desperdício de água de boa qualidade, ii) desordenado e elevado crescimento da população principalmente em regiões áridas, mais pobres e menos desenvolvidas e iii) consumo exagerado pelo setor industrial. A água está se tornando uma das mercadorias mais valiosas do século 21 , cuja demanda tende a aumentar e a oferta se mostra cada vez mais reduzida. A água passa a ser considerado um recurso de elevado valor social, econômico e ecológico, enquanto as taxas de consumo e o crescimento da população se elevam em razão geométrica de 1,6\% ao ano. De acordo com a elevação deste índice, o esgotamento do potencial hídrico ocorrerá por volta do ano 2053 (REBOUÇAS, 2003)

Frente a todas estas questões de escassez das reservas naturais, aumento da demanda por ordem de crescimento da população, industrial e agrícola, resta à sociedade atual, líderes políticos e estudiosos do problema lançar ações que possam ajudar na implantação de técnicas ambientais que melhorem o desenvolvimento humano em sua vivência sustentável.

Os precursores na reutilização de águas foram os Estados Unidos, porém outros países estão caminhando rumo à sustentabilidade e estão buscando formas de implantar o reúso em diferentes setores como a agricultura, as indústrias fins menos nobres. 0 Brasil e o México seguem este exemplo e prosseguem pesquisando formas de reutilização da água (BLANCO, 2007). Segundo Telles e Costa (2007) o Brasil caminha lentamente na direção da sustentabilidade, ou seja, no uso inteligente da água, todavia, é uma realidade que esbarra em contextos políticos e na dificuldade de integração das organizações públicas e privadas.

Ao se pensar em aplicar uma nova técnica deve-se primeiramente avaliar a relação custo $x$ benefício que se pode alcançar. A utilização de técnicas que visam à reutilização da água é uma das opções mais inteligentes para racionalização dos recursos hídricos, sendo uma ação totalmente engajada na sustentabilidade, que por conseqüência retorna 
na forma de custo x beneficio, quando se pensa em escassez de água, má distribuição, recursos hídricos finitos e manutenção do ciclo produtivo agroindustriais.

Embora diversos fatores determinem como o uso da água será realizado, a eficiência do seu uso pode variar conforme a região, estação climática ou preço relativo deste recurso. É claro que em regiões áridas e semiáridas a necessidade de água é bem maior do que em regiões úmidas, portanto, o uso bem planejado irá viabilizar os diversos setores produtivos. O monitoramento da quantidade e da qualidade da água está estreitamente relacionada à eficiência do uso e quando o recurso é avaliado corretamente há um incremento de tecnologia incentivando a produtividade (PAZ, TEODORO e MENDONÇA, 2000).

Segundo Dantas e Sales (2009, p. 7) para a questão da água "o seu reúso é uma das possibilidades de compromisso para reversão do quadro de escassez, sendo uma das maneiras de unir comprometimento social e ambiental”. O reúso é uma ferramenta de extrema importância na busca de controle de perdas e desperdícios, diminuição dos elevados volumes de efluentes produzidos e do consumo de água. A demanda crescente tem exigido um reúso planejado, mais racional e eficiente a fim de garantir a conservação dos recursos e acrescentar vantagens econômicas.

Telles e Costa (2007) abordam em seus estudos a questão da demanda de água para a produção de alimentos que vem aumentando progressivamente, sendo que uma das principais alternativas de reúso se aplica na agricultura. A utilização do efluente tratado para a irrigação auxilia na diminuição dos grandes volumes gerados e que seriam descartados diretamente nos corpos hídricos, racionalizam o uso da água potável, auxiliam no controle da poluição e de impactos ambientais, contribuem para o aumento da área cultivada e o aumento da produção e viabilizam a agricultura em regiões onde há carência de água.

O reúso da água ainda é uma questão que necessita de muito estudo para se viabilizar, no entanto, já existem diversas aplicações para tal técnica. Entretanto, estas ações ainda estão associadas a iniciativas isoladas e a maioria das quais, dentro do setor privado. Estas ações isoladas são extremamente eficazes no que diz respeito, por exemplo, ao reúso industrial utilizando seu próprio efluente e o transformando em água apta à reutilização. 


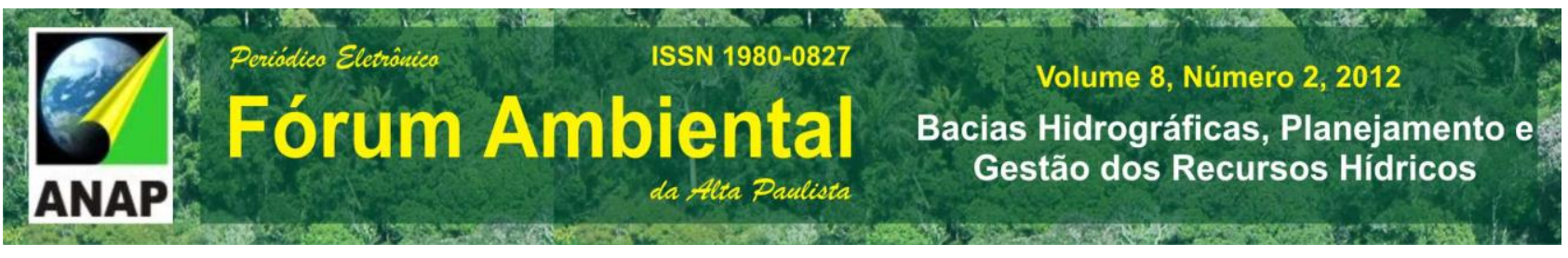

\subsection{Aplicação do reúso como prática sustentável em diferentes setores}

Segundo Weber, Cybis e Beal (2010) a partir da implantação da Lei 9.433, de 1997, foi instituída a cobrança pelo uso dos recursos hídricos no Brasil. Esta lei veio a corroborar para tomada de ações planejadas de reúso de águas resíduárias, conceito este praticado há muitos anos em todo o mundo. A implantação desta lei para a prática de reúso vem a calhar com as quantidades de água que são utilizadas para os mais fundamentais setores da economia. De acordo com Mancuso e Santos (2003) 65\% de toda a água consumida é destinada ao setor agrícola, 25\% às indústrias e os $10 \%$ restantes são encaminhados para os diversos fins urbanos.

O uso de efluentes para abastecer o setor industrial com água de reúso possuí fins benéficos, pois este uso pressupõe a utilização de uma água de menor qualidade em relação a água potável, mas que seria descartada sem qualquer utilização e que constitui uma alternativa para que sejam satisfeitas demandas menos restritivas quanto à potabilidade e qualidade (WEBER, CYBIS, BEAL, 2010). Além de diminuir o desperdício da água, o reúso tem a potencial capacidade de reduzir a emissão de poluentes industriais nos corpos hídricos quando a água de reúso é incorporada em alguma etapa adjacente do processo de produção. Para Mancuso e Santos (2003) se houvesse a redução de $10 \%$ da água destinada ao setor agrícola, aliada com a implementação de técnicas modernas de irrigação e suporte governamental seria possível, no mínimo, duplicar a quantidade de água destinada ao consumo doméstico em escala mundial.

$\mathrm{Na}$ industria, os setores com maior potencial de aproveitamento de águas de reúso são: torres de resfriamento; caldeiras; construção civil, para cura de concreto, compactação do solo e irrigação de áreas verdes. Para a empresa, o tratamento de efluentes é o principal meio de reaproveitamento de um recurso que seria desperdiçado e que possui um elevado custo e que certamente, em curto prazo de tempo, será um bem racionado (BRAGA et al, 2005).

Assim, perante as alternativas tão eficazes e simples de reutilização dos recursos hídricos que são perdidos, o planejamento e a ação do homem são os elementos chaves para tornar estas alternativas viáveis e aplicáveis, garantindo a evolução das 


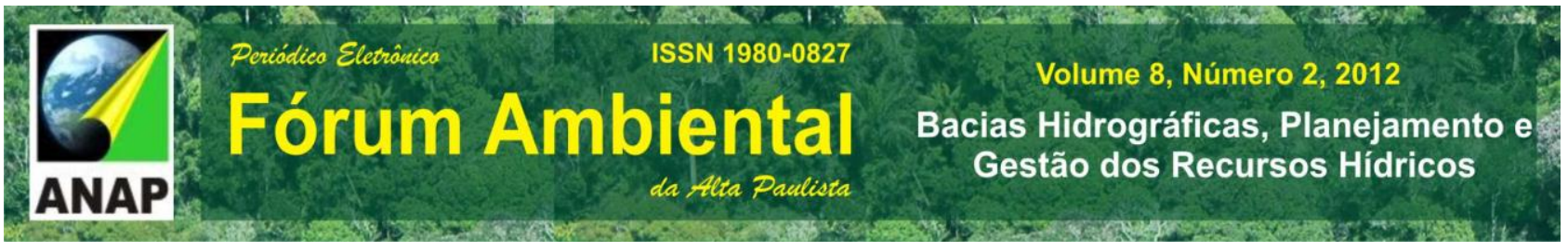

necessidades de água nos diferentes setores de atividades que geram o desenvolvimento sócio-econômico nacional e regional.

Neste contexto, Pacheco (2006) pontua que a comunicação entre o setor industrial e órgãos ambientais é fundamental para o desenvolvimento de práticas e idéias para que se possam alcançar soluções adequadas para as questões e problemas de ordem ambiental, bem como na manutenção do desenvolvimento social e econômico sustentável. Espera-se que este intercâmbio de informações e tecnologia sustentável gerem uma visão mais crítica por parte do setor produtivo industrial e da sociedade para que possam identificar oportunidades de melhorias nos processos produtivos a fim de se obter cada vez mais o desenvolvimento de técnicas que visam a produção mais limpa e menos impactantes para o meio ambiente.

A sociedade precisa se conscientizar de que as vantagens em se produzir sustentavelmente são para todos, desde o indivíduo à sociedade, do país ao planeta. Para o setor industrial os benefícios são: a redução dos custos de produção; o aumento da eficiência e competitividade de mercado, a diminuição dos riscos de acidentes ambientais, as melhorias nas condições de saúde e na segurança do trabalhador, na imagem da empresa junto a consumidores, fornecedores, poder público, mercado e comunidades internas e externas, mais acesso a linhas de financiamento e melhoria do relacionamento com órgãos ambientais e com toda a sociedade. Todas estas vantagens acarretam em uma produção mais limpa e sustentável e deve ser o principal caminho a ser seguido pelas empresas (PACHECO, 2006).

\section{POSSIBILIDADES E INICIATIVAS DE REÚSO: PRÁTICAS SUSTENTÁVEIS QUE BENEFICIAM A SOCIEDADE E O MEIO AMBIENTE} definição:

Segundo o Codex Alimentarius (2001) a água de reúso possuí a seguinte "É a água que tenha sido recuperada de uma etapa de processamento, inclusivo
de componentes de alimentos, e que após subseqüentes tratamentos de
recondicionamento, se necessários, é destinado a ser re(usado) no mesmo,
anterior ou subseqüente operação do processamento de alimentos. Agua de reúso
inclui água recirculada, água reciclada e água recuperada" (CODEX
ALIMENTARIUS, 2001). 


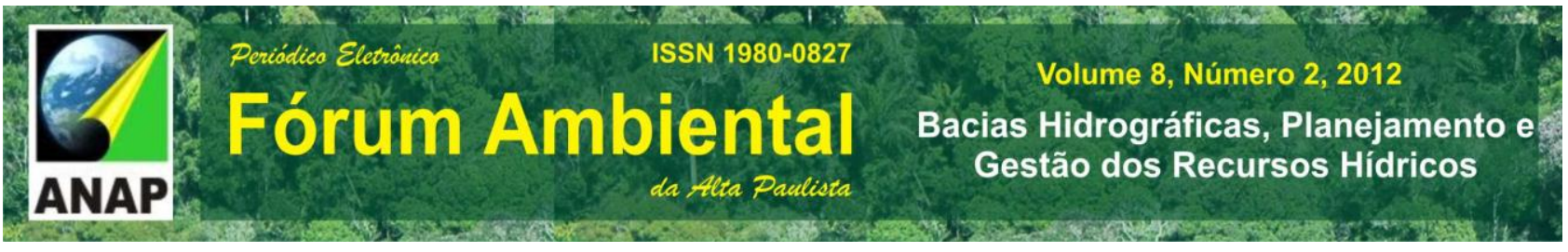

O reúso da água pode garantir e fornecer uma ampla gama de benefícios para as comunidades, o qual pode ser traduzido na criação de grandes valores para a sociedade e para o meio ambiente. No entanto, os benefícios do reúso podem ser difíceis de serem quantificados e freqüentemente ainda não são reconhecidos. Um dos benefícios mais significantes do reúso da água é a sua utilização em projetos e planejamentos de políticas voltadas aos recursos hídricos e aos programas de inclusão de projetos que viabilizam a busca pela sustentabilidade no abastecimento de águas (MILLER, 2006).

Ainda de acordo com o contexto exposto por Miller (2006) a iniciativa de reúso de águas precisa derrubar barreiras, quando se trata de conceitos de integração, os quais envolvem convergências de áreas como a governamental, a saúde pública, as regulamentações e as políticas públicas ambientais.

Diversos exemplos de experiências da aplicação do reúso de água, ao redor do mundo, apresentam os quesitos necessários para a sua realização: a necessidade de inovações tecnológicas e a transferências de tecnologias entre as nações que a aplicam e possuem bons resultados. Para novas aplicações, em diferentes contextos, é necessária a educação da sociedade, o aumento da aceitação pública, melhores legislações a respeito dos benefícios do reúso da água, a inserção de financiamentos para os projetos e o suporte de políticas regulamentadoras (MILLER, 2006).

Telles e Costa (2007) são taxativos em definir que o Brasil, de maneira geral, é um país rico em recursos hídricos e possui grande potencial de água doce, que deve ser visto como capital ecológico de valor inestimável para o desenvolvimento sócioeconômico do país. Porém, o que falta no Brasil não é a água, mas sim a consciência ética e maior interesse dos governantes, da sociedade e do poder econômico a fim de otimizar estes recursos naturais abundantes, prevenindo um futuro de escassez com alternativas inteligentes e mais eficientes de reúso da água, buscando o desenvolvimento sustentável.

Embora existam muitas possibilidades de se aplicar o reúso de água, no Brasil, em busca de se atender a variedade de usos benéficos, os setores que mais utilizam a água de reúso, são as áreas urbanas, indústrias, agricultura e o reúso associado à recarga de aqüíferos (MANCUSO e SANTOS, 2003). 


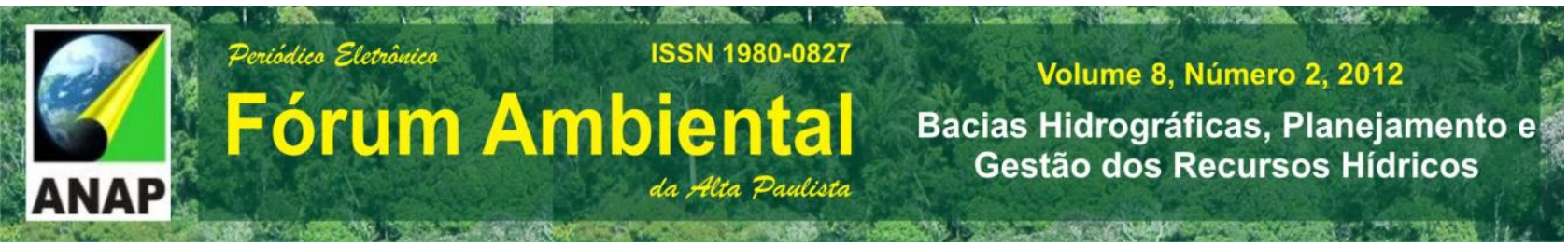

Exemplos de reúso de água podem ser vistos no Brasil e no mundo, com práticas simples como a recirculação de esgoto secundário de pisos e pias para a descarga de vasos sanitários. O aeroporto de Guarulhos (SP) demonstrou ser possível realizar um trabalho de reciclagem para a utilização em descargas, lavagem de pista e aeronaves e sistema de resfriamento. Na Europa, a Comunidade Econômica Européia pretende implantar um programa para a remoção de produtos farmacêuticos e de higiene pessoal dos esgotos e das instalações de tratamento de água, conhecido como Poseidon (MANCUSO e SANTOS, 2003). O projeto Poseidon objetiva aumentar a utilização indireta da água de reúso pela eliminação de resíduos dos produtos farmacêuticos e de higiene pessoal PPCPs, (Pharmaceuticals e Personal Care Product Ingredients), que não são retirados através dos processos usualmente aplicados no tratamento de esgotos e que contaminam a água de abastecimento e os aquíferos (EU, 2003).

No setor alimentício o reúso é restringido ao sistema direto ou indireto para que operações que envolvam a água de reúso não entre em contato com o produto a ser consumido e tão somente em sistemas de resfriamentos, irrigações, descargas sanitárias entre outros. Para este segmento existem regulamentações restritas por ordem da segurança alimentar, contudo órgãos regulamentadores internacionais permitem o uso seguro de reúso de água neste ramo tanto quanto o uso de água não potável, desde que a água de reúso apresente qualidade requerida na operação, no método de recuperação e distribuição e na capacidade para recondicionar a água ao nível requerido (LUIZ, 2007).

O reúso industrial pode ser visualizado sob múltiplos aspectos, conforme as possibilidades existentes no contexto interno e externo de cada indústria. De acordo com Mancuso e Santos (2003), a água que seria descartada pode se adaptar a um novo uso mediante tratamento adequado podendo constituir um manancial alternativo, particularmente para fins industriais, ampliando a economia da empresa em relação aos custos com água potável e tratamento de resíduos que seriam descartados sem o mínimo de utilização.

As variadas formas de reúso industrial podem ser divididas em reúso macroexterno, macro-interno e interno específico. Nos sistemas macro-externos a água de reúso será utilizada nas torres de resfriamento, caldeiras, lavagem de peças e equipamentos do setor mecânico, irrigação de áreas verdes, lavagem de pisos da área 


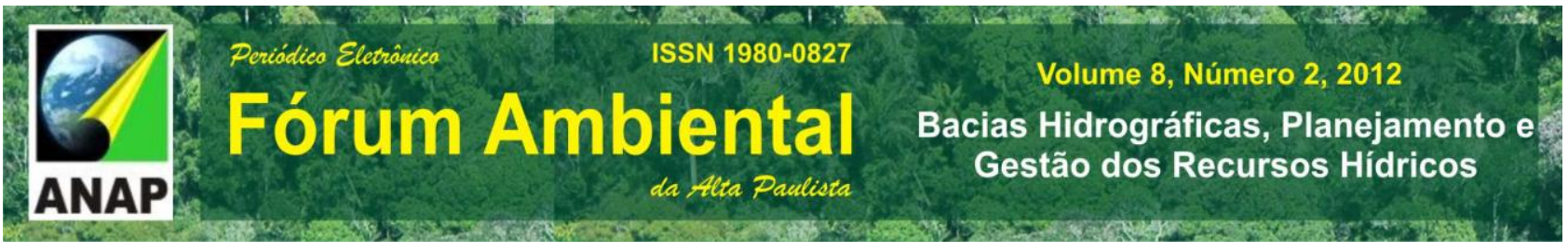

externa e veículos e processos industriais. Nos sistemas macro-interno a utilização se dá primeiramente em torres de resfriamento, visando a redução do consumo de água e em seguida será empregada para a diminuição das cargas de poluentes. Os sistemas interno específico consiste em utilizar a água de reúso em qualquer processo industrial, na manutenção da estação de tratamento de efluente, em processos que suportam a qualidade compatível com o efluente em consideração, como em operações de pintura automobilísticas, águas de lavagens sucessivas, dentre outras (MANCUSO e SANTOS, 2003).

O reúso é uma ferramenta de extrema importância na busca do controle de perdas e desperdícios, na diminuição dos elevados volumes de efluentes produzidos e do consumo de água. A demanda crescente de água tem exigido um reúso planejado, mais racional e eficiente que possa vir a garantir a conservação dos recursos naturais e acrescentar uma vantagem econômica.

A recuperação e reúso de águas residuárias são geralmente definidas de acordo com os padrões de distribuição de água ou recomendado pelas autoridades locais ou agencias internacionais. A recuperação de efluentes pode ser utilizada em diferentes aplicações, desde que seja especificado a qualidade desta água e qual será sua finalidade. Para cada categoria de uso deverá ser especificado os limites microbiológicos e químicos, sendo avaliados os custos analíticos e a frequência de análise dos parâmetros mais importantes. Cabe ressaltar que os estudos ainda são limitados e que requer melhor avaliação do reúso originado de efluentes no que diz respeito aos riscos microbiológicos e químicos. Os parâmetros microbiológicos são insuficientes para determinar completamente os riscos deste uso, pois são necessárias mais informações quanto à presença de parasitas e vírus e a lista de parâmetros químicos pode ser incompleta ou excessiva, sendo necessária a busca por indicadores adequados (SALGOT et al, 2005).

Em um futuro breve, a água certamente será considerada um artigo de luxo e altamente valorizada, sendo raras as possibilidades de encontrá-la a um baixo custo. Esta elevação de valores será o propulsor para a implantação e execução do reúso e reciclo da água, principalmente no setor industrial que exigirá o desenvolvimento de novas tecnologias para tornar estas operações viáveis, pois para trata - lá são necessários altos 
investimentos. O reúso certamente será uma ferramenta bastante apropriada, mas para isto depende de incentivos econômicos em larga escala (LUIZ, 2007).

\section{CARÊNCIA DE REGULAMENTAÇÕES PARA O REÚSO DA ÁGUA}

Para a utilização dos recursos hídricos é importante a existências de normas que possam garantir a relação harmônica existente entre as atividades antrópicas e o meio ambiente, além de manter o equilíbrio entre os mais variados setores econômicos da sociedade (FIESP/CIESP, 2004).

Dentro do estado de São Paulo, com a aprovação da Lei Estadual n 7.663/91 foi dado início ao processo de implantação do Conselho Estadual de Recursos Hídricos (nível central) que criou o Comitê de Bacias Hidrográficas (nível regional). A partir de 1994 iniciou-se efetivamente os trabalhos visando adequação de uma política em prol dos recursos hídricos e em 1997 foi instituída a Lei Federal n 9.433/97 da Política Nacional dos Recursos Hídricos que criou o Sistema Nacional de Gerenciamento de Recursos Hídricos integrado por colegiados de decisões com importante participação da população, órgãos públicos federais, estaduais, municipais e agências de águas.

Com relação ao reúso de água, o Conselho Nacional de Recursos Hídricos do Ministério do Meio Ambiente, por meio da Resolução n 54 de 28 de novembro de 2005, estabeleceu as modalidade, as diretrizes e os critérios gerais que regulamentam e estimulam a sua prática para fins não potáveis, em todo território nacional. Resolve também que deverão ser incentivados e promovidos programas de capacitação, mobilização social e informação quanto à sustentabilidade do reúso, em especial os aspectos sanitários e ambientais.

A Superintendência de Cobrança e Conservação (SCC) da Agencia Nacional de Águas pretende iniciar um processo de divulgação das tecnologias de reúso de águas no Brasil, porém ainda não existem incentivos para as atividades de reúso de água utilizando efluentes pós-tratados. Desta forma, existe uma imediata necessidade de criação de estruturas de gestão, legislação, informação e desenvolvimento de tecnologias 
compatíveis com as condições técnicas, culturais e sócio-econômicas do país (TELLES e COSTA 2007).

Para a conservação da água é importante em um primeiro momento reduzir o seu consumo de maneira racional, para posteriormente avaliar a implantação do seu reúso. A implantação de um programa de conservação e de reúso de água no setor industrial pode trazer grandes benefícios econômicos, o que influencia diretamente o aumento da eficiência produtiva e consequentemente a redução do consumo de água, do volume de efluente gerado, além de menor consumo de energia e produtos químicos (FIESP/CIESP, 2004).

Além do estabelecimento de regras para a utilização do reúso de água necessitase de uma política de educação ambiental voltada para a prática do reúso. A percepção e a opinião pública podem impulsionar o sucesso ou o fracasso do reúso, fato este que deve ser levado em conta durante todo o planejamento e implantação de programas de reúso. Deste modo, as ações que promovem o conhecimento da sociedade no que diz respeito aos benefícios do reúso no dia a dia da população e na proteção ao meio ambiente e saúde pública devem ser entendidas e aceitas por todos (RODRIGUES, 2005).

Além da regulamentação para a prática do reúso no Brasil é preciso a criação de um programa de educação ambiental voltado ao estímulo à participação da comunidade na implementação de diversos projetos de reúso. De acordo com o artigo 1, da Lei Federal $n^{\circ}$ 9795/99, que institui a Política Nacional de Educação Ambiental, regulamentada pelo Decreto $\mathrm{n}^{\circ} 428 / 02$, a Lei define educação ambiental como "os processos pelos quais 0 indivíduo e a coletividade constroem valores sociais, conhecimentos, habilidades, atitudes e competências voltadas para a conservação do meio ambiente, bem como uso comum do povo, essencial à qualidade de vida sadia e sua sustentabilidade".

\section{CONSIDERAÇÕES FINAIS}

O reúso da água surge como uma solução necessária para a questão da escassez que pode auxiliar a minimizar os problemas de racionalização através da 
utilização de água de qualidade inferior para fins não tão nobres. A utilização de práticas como estas auxiliam diretamente na diminuição da pressão dos aquíferos. A prática do reúso atualmente está sendo difundida e aplicada em diferentes setores econômicos 0 que auxilia diretamente a manutenção das reservas hídricas e potencializa o uso de recursos que seriam descartados.

As ações para implantação do reúso devem ser tomadas por órgãos regionais, a fim de aumentar a sua eficiência e proporcionar uma maior agilidade no processo de decisões quanto a sua devida aplicação e função, sejam estas nos setores industriais, agrícolas ou doméstico.

Visando o crescimento do reúso no Brasil e aumento de seus benefícios torna-se fundamental um direcionamento legal e institucional para a regulamentação desta prática, bem como o gerenciamento dos recursos hídricos, saneamento, educação ambiental e a proteção do meio ambiente.

O programa de educação ambiental, voltado para o reúso, deve atuar como uma garantia de divulgar os benefícios e riscos decorrentes de sua implementação para que a opinião pública possa ter condições de avaliar e emitir seu parecer, apoiando ou não esta prática.

\section{REFERENCIAS}

BLANCO, M. Água Reciclada, Economia para o Futuro. Revista Aqua Vitae online, Ano 3, n. 04, mar. 2008. Disponível em: < http://www.aquavitae.com/materia/ler/ agua_reciclada_economia_para_o_futuro>. Acesso em 28 set. 2012.

BRAGA, B. et al. Introdução à Engenharia Ambiental, 2. ed. São Paulo: Person Prentice Hall, 2005.

BRASIL. Lei $n^{\circ}$ 9.433, de 8 de janeiro de 1997, Institui a Política Nacional de Recursos Hídricos, cria o Sistema Nacional de Gerenciamento de Recursos Hídricos, regulamenta o inciso XIX do art. 21 da Constituição Federal e altera o art. $1^{\circ}$ da Lei $n^{\circ} 8.001$, de 13 de março de 1990, que modificou a Lei n 7.990, de 28 de dezembro de 1989. Diário Oficial da Unnião, Brasília, DF.

BRASIL. Resolução, $n^{\circ}$ 54, de 28 de novembro de 2005, Estabelece modalidades, diretrizes e critérios gerais para a prática de reúso direto não potável de água, e dá outras providencias. Diário Oficial da União, Brasília, DF. 
BRASIL. Lei n 7.663, de 30 de dezembro de 1991, Estabelece normas de orientação á Política Estadual de Recursos Hídricos bem como ao Sistema Integrado de Gerenciamento de Recursos Hídricos. Diário Oficial da União, Brasília, DF.

BRASIL. Lei Federal $\mathrm{n}^{\circ}$ 9795, de 27 de abril de 1999 - Dispõe sobre a educação ambiental, institui a Política Nacional de Educação Ambiental e dá outras providências. Diário Oficial da União, Brasília, DF.

BRASIL. Decreto $n^{\circ}$ 4.281, de 25 de junho de 2002 - Regulamenta a Lei n 9.795, de 27 de abril de 1999, que institui a Política Nacional de Educação Ambiental e dá outras providências, Diário Oficial da União, Brasília, DF.

CODEX ALIMENTARIUS. Codex Alimentarius Commission: Codex Committee on Food Hygiene. Proposed Draft Guidelines for the Hygienic Reuse of Processing Water in Food Plants. Joint FAO/WHO Food Standards Programme, 34th Session, Bangkok, Thailand, 2001.

DANTAS, L.D.; SALES, C.W.A. Aspectos ambientais, sociais e jurídicos do reúso da água. Revista de Gestão Social e Ambiental, São Paulo, v.3, n. 3, p. 4-19, set./dez. 2009.

EU - PROJECT POSEIDON. Disponível em: < http://www.poseidon.geo.unimainz.de/contact.htm> Acesso em 15/set/2012.

FIESP/CIESP. Conservação e Reúso de Água - Manual de Orientações para o Setor Industrial. São Paulo, v.1, 2004.

LUIZ, B.D.D. Gerenciamento Hídrico em Frigoríficos. 2007, 115f. Dissertação (Mestrado em Engenharia Química), Universidade Federal de Santa Catarina. Florianópolis.

MANCUSO, S.C.P.; SANTOS, D.F.H. Reúso de Água. Barueri: Editora Manole, 2003.

MILLER, W, G. Integrated concepts in water reuse: managing global water needs. Desalination, Amsterdam, v. 187, n. 1-3, p. 65-75, fev. 2006.

PACHECO, W. J. Guia Técnico Ambiental de Frigoríficos - industrialização de carnes (bovina e suína). Séria $(P+L)$, 85p, São Paulo, CETESB, 2006. Disponível em: <http:www.cetesb.sp.gov.br>. Acesso em: 28/ag/2012.

PAZ, S. da P. V.; TEODORO, F. E. R.; MENDONÇA, C. F. Recursos Hídricos, Agricultura Irrigada e Meio Ambiente. Revista Brasileira de Engenharia Agrícola e Ambiental, Campina Grande, v. 4, n. 3, p. 465-473, set./dez. 2000.

REBOUÇAS, C.A. Água no Brasil: abundância, desperdício e escassez. Revista Bahia Análise \& Dados, Salvador, v.13, ํo especial, p. 341-345, 2003. 
RODRIGUES, S.R. As Dimensões Legais e Institucionais de Reúso de Água no Brasil. 2005, 192f. Dissertação (Mestrado em Engenharia Hidráulica e Sanitária), Escola Politécnica da Universidade de São Paulo - USP, São Paulo.

SALGOT, M. Wastewater reuse and risk: definition of key objetives. Desalination, Amsterdam, v. 187, n. 1-3, p. 29-40, fev. 2006.

SPIRO, T. G.; STIGLIANI, W. M. Química Ambiental. 2. ed. São Paulo: Pearson Prentice Hall, 2008-2009.

TELLES, A.D; COSTA, G.P.H.R. Reúso da água: Conceitos, teorias e práticas. 1.ed. São Paulo: Blucher, 2007.

WEBER, C.C.; CYBIS, F.L.; BEAL, L.L. Reúso da água como ferramenta de revitalização de uma estação de tratamento de efluentes. Revista Engenharia Sanitária Ambiental, Rio de Janeiro, v. 15, n. 2, p. 119-128, abr./jun. 2010. 